preterm infants, might be non-specific, which might include temperature instability, gastrointestinal and cardiovascular dysfunction, and dominant respiratory problems. Some severe patients could rapidly develop acute respiratory distress syndrome. All infants with suspected COVID-19 should be isolated and monitored regardless of whether or not they present with symptoms. Diagnosis of neonatal COVID-19 could be confirmed if the suspected patients have positive nucleic acid test for COVID-19 from the respiratory tract, stool or blood specimens. ${ }^{4}$

Infants with highly suspected or confirmed COVID-19 should be referred to the designated neonatal ward. All medical staff involved should wear protective equipment. The neonatal department should be strictly stratified into transitional, quarantine, living and work areas. Infants with suspected infection should be isolated in a single room, while confirmed patients should be moved into separate rooms. The quarantine room should be equipped with an isolated air cycle system. Due to the strong infectivity of COVID19 , negative pressure isolation rooms are recommended.

After admission, the following prevention and control strategies should be adequately performed. Protective equipment including hats, goggles, long-sleeved protective suits, gloves and medical masks must be available for all medical staff. Minimal number of people in the isolated area and the necessary operation clusters are preferred. Avoid breast feeding from COVID-19 mother until recovery. Strict hand hygiene and disinfecting environment protocol are required.

The patients could be discharged if the following requirements are met: (1) the temperature returned to normal for more than 3 days; (2) respiratory symptoms and chest radiography improved dramatically; (3) nasopharyngeal and pharyngeal swabs, and sputum show negative for COVID-19 for two consecutive times (with at least a 24-hour interval).

COVID-19 outbreak might bring psychological stress to the patient's parents and medical staff. Appropriate psychological support is needed.

Due to the limited cases and clinical evidence in neonatal COVID-19, the proposal will be continuously modified based on accumulated clinic evidence and experience.

\section{Fang $\mathrm{Li}^{1,2}$ Zhi Chun Feng, ${ }^{3}$ Yuan Shi ${ }^{1,2}$}

${ }^{1}$ Department of Neonatology, Chongqing Medical University Affiliated Children's Hospital, Chongqing, China
${ }^{2}$ National Clinical Research Center for Child Health and Disorders, Chongqing, China

${ }^{3}$ Bayi Children's Hospital, The Seventh Medical Center of Chinese PLA General Hospital, Beijing, China

Correspondence to Professor Yuan Shi, Department of Neonatology, Chongqing Medical University Affiliated Children's Hospital, Chongqing 400014, China; shiyuan@hospital.cqmu.edu.cnProfessor Zhi Chun Feng; zhichunfeng81@163.com

Acknowledgements Thanks to the help by Chinese Neonatologist Association of Chinese Doctor Association.

Contributors $\mathrm{FL}$ is responsible for writing the manuscript. YS and ZCF are responsible for censorship, organising and contacting on Chinese Neonatologist Association of Chinese Doctor Association.

Funding The authors have not declared a specific grant for this research from any funding agency in the public, commercial or not-for-profit sectors.

Competing interests None declared.

Patient consent for publication Not required.

Provenance and peer review Not commissioned: internally peer reviewed.

\section{(2) OPEN ACCESS}

Open access This is an open access article distributed in accordance with the Creative Commons Attribution Non Commercial (CC BY-NC 4.0) license, which permits others to distribute, remix, adapt, build upon this work non-commercially, and license their derivative works on different terms, provided the original work is properly cited, appropriate credit is given, any changes made indicated, and the use is non-commercial. See: http://creativecommons.org/ licenses/by-nc/4.0/.

(C) Author(s) (or their employer(s)) 2020. Re-use permitted under CC BY-NC. No commercial re-use. See rights and permissions. Published by BMJ.

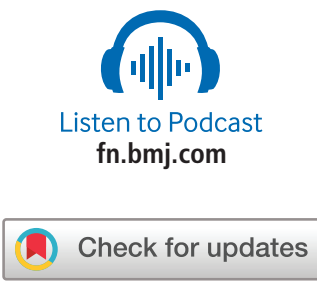

To cite Li F, Feng ZC, Shi Y. Arch Dis Child Fetal Neonatal Ed 2020;105:F683-F684.

Accepted 20 February 2020

Published Online First 4 March 2020

Arch Dis Child Fetal Neonatal Ed 2020;105:F683F684.

doi:10.1136/fetalneonatal-2020-318996

\section{REFERENCES}

1 Zhu N, Zhang D, Wang W, et al. A novel coronavirus from patients with pneumonia in China, 2019. N Engl J Med 2020;382:727-33.

2 Fang F, Luo XP. Facing the pandemic of 2019 novel coronavirus infections: the pediatric perspectives. ZhonghuaErKeZaZhi 2020;58:E1.

3 Shek CC, Ng PC, Fung GPG, et al. Infants born to mothers with severe acute respiratory syndrome. Pediatrics 2003;112:e254 


\section{PostScript}

4 World Health Organization. Interim clinical guidance

for management of patients with confirmed 2019 novel

coronavirus (2019-nCoV) infection, 2020. Available:

https://www.cdc.gov/coronavirus/2019-ncov/hcp/

clinical-guidance-management-patients.htm; 